\title{
Amaranthus hybridus can be pollinated frequently by $A$. tuberculatus under field conditions
}

\author{
F Trucco, MR Jeschke, AL Rayburn and PJ Tranel \\ Department of Crop Sciences, University of Illinois, 240 Edward R. Madigan Laboratory, 1201 West Gregory Drive, Urbana, \\ IL 61801, USA
}

\begin{abstract}
Recent studies have confirmed that weedy Amaranthus species are capable of interspecific hybridization, and such hybridization may foster the evolution of herbicide resistance. However, the extent to which hybridization among these species occurs in nature is unknown. The purpose of this study was to determine the frequency under field conditions at which $A$. hybridus, a monoecious and predominantly selfpollinated species, would be pollinated by $A$. tuberculatus, a dioecious species. To do this, parents carrying different alleles at the $A L S$ locus, which encodes a herbicide target site, were used. Male $A$. tuberculatus parents were homozygous for a dominant herbicide-insensitive allele, while $A$. hybridus parents were homozygous for a sensitive form. Hybrid progeny therefore could be detected via herbicide
\end{abstract}

selection. Mean hybridization frequencies between 0.4 and $2.3 \%$ were obtained, depending on the proximity between parents $(P=0.02)$. The robustness of the hybrid selection assay was verified using a molecular marker and DNA content analyses. Using these techniques, more than $99 \%$ of the progeny that survived the herbicide were confirmed to be hybrids. Frequencies obtained in this study were many times higher than the generally expected rate of mutation. Therefore, even minimal fertility in hybrid progeny would support the view that hybridization could play a role in adaptive evolution of weedy Amaranthus species.

Heredity (2005) 94, 64-70. doi:10.1038/sj.hdy.6800563

Published online 18 August 2004

Keywords: Hybridization; Amaranthus tuberculatus; Amaranthus rudis; Amaranthus hybridus; gene flow; herbicide resistance

\section{Introduction}

A species' ability to evolve in response to changing environmental conditions is found in the genetic diversity of its populations. Success in weed populations facing changing agricultural ecosystems often correlates with abundance of genetic polymorphisms within those populations (Jasieniuk and Maxwell, 2001). De novo genetic diversity can be acquired through a number of different mechanisms that include enzymatic errors at replication, meiotic recombination, and transposable element activity. Additionally, a species' genetic variability could reflect the ability of that species to acquire new allelic forms via introgression.

Gene flow between domesticated plants and their wild relatives has been studied extensively in efforts to establish the likelihood of transgene escape from genetically modified crops (Jørgensen and Andersen, 1994; Whitton et al, 1997; Seefeldt et al, 1998; Ellstrand, 2001; Rieger et al, 2001; Spencer and Snow, 2001). Although several studies have characterized hybrids between related weed species, the frequencies of spontaneous hybridization between such species have been seldom addressed (Darmency, 1996).

The genus Amaranthus includes several weed species that, collectively, are distributed throughout the world. In Illinois, the two most problematic Amaranthus species

Correspondence: PJ Tranel, Department of Crop Sciences, University of Illinois, 240 Edward R. Madigan Laboratory, 1201 West Gregory Drive, Urbana, IL 61801, USA. E-mail: tranel@uiuc.edu

Received 20 November 2003; accepted 14 June 2004; published online 18 August 2004 in agronomic crops are $A$. tuberculatus and $A$. hybridus (Wax, 1995; Hager et al, 2002). A. tuberculatus is native to North America and found predominantly in the Midwestern United States (Sauer, 1957). A. hybridus is of world-wide distribution, being found in areas of South, Central, and North America, eastern Asia, Australia, and Africa (Sauer, 1967). Both species are annual herbaceous plants with high reproductive output; a single plant may produce over 100000 seeds. Seeds germinate in several flushes beginning in spring and extending well into the growing season, particularly for A. tuberculatus (Hager et al, 1997). Multiple flushes of germination result in plants at different developmental stages and overlapping flowering times of the two species. Both species are primarily wind pollinated (Murray, 1940). Being dioecious (separate male and female plants), A. tuberculatus is an obligate outcrosser. $A$. hybridus has separate male and female flowers (monoecism); however, due to the proximal arrangement of these flowers, it is thought to be mostly self-pollinated.

Several scientists have investigated hybridization between different amaranths and described the relative ease with which it can occur, yet all research has fallen short from establishing field frequency of occurrence (Murray, 1940; Sauer, 1957; Wetzel et al, 1999; Franssen et al, 2001; Tranel et al, 2002). Moreover, the fate of hybrids and their evolutionary significance have yet to be fully explored. The difficulty in distinguishing Amaranthus hybrids from nonhybrids based on morphological features has contributed to the lack of information in this area.

Hybridization among weedy amaranths is hypothesized to increase genetic variation and allow these species to adapt more quickly to cropping systems. In 
particular, recent studies have shown that hybridization among some Amaranthus species may be a route for acquisition of resistance to various herbicides (Wetzel et al, 1999; Franssen et al, 2001; Tranel et al, 2002). Regardless of the potential adaptive advantage of hybridization, its evolutionary impact is dependent on its frequency of occurrence. For instance, if hybridization were to occur at frequencies lower than the generally expected rate of mutation $-10^{-6}$ for ALS mutations conferring herbicide resistance (Gressel, 2002) - its impact might be rather trivial. On the other hand, if frequencies are shown to be substantially higher, hybridization could play a predominant adaptive role.

The purpose of this study was to determine the frequency under field conditions at which the predominantly self-pollinated $A$. hybridus could be pollinated by the dioecious $A$. tuberculatus. Since hybridization was assessed in the direction where $A$. hybridus acted as the female parent, production of hybrid seed was expected to be a very rare occurrence. Therefore, to accomplish the goal of this study, field crosses were designed using specific parental biotypes such that hybrid progeny would exhibit resistance to acetolactate synthase (ALS)inhibiting herbicides. Resistance to these herbicides, in the form of a mutation in the ALS gene, has been selected in populations of $A$. tuberculatus (Foes et al, 1998) (As suggested by Pratt and Clark (2001), A. tuberculatus and $A$. rudis are now considered synonymous.) and numerous other weed species (Guttieri et al, 1996). Herbicide resistance in hybrids permits the use of herbicide selection to discriminate hybrids from nonhybrid progeny, resulting in high-throughput hybrid detection. Hybrid identity was further verified using two additional tools: molecular analysis of the ALS gene based on a restriction enzyme polymorphism, and cytogenetic analysis based on the different DNA contents of $A$. hybridus, A. tuberculatus, and their hybrids.

\section{Materials and methods}

\section{Plant material}

One population of each species was used for this study. The $A$. hybridus population was obtained by selfing herbicide-susceptible parents grown from seed collected in an Illinois field. The $A$. tuberculatus population used was derived from that described by Foes et al (1998), and it contained resistance to ALS-inhibiting herbicides, such as chlorimuron-ethyl. Samples from both populations were tested with a $90 \mathrm{~g} / \mathrm{ha}$ rate of chlorimuron-ethyl to confirm their herbicide susceptibility/resistance.

\section{Field hybridization experiment}

Seedlings were started in the greenhouse and transplanted to field plots at three different timings to ensure overlapping flowering periods. Each year, the first timing was transplanted on July 1, 3 weeks after greenhouse initiation, when seedlings were $10-15 \mathrm{~cm}$ tall. Additional seedlings were transplanted on July 10 and 20. The first timing included only $A$. tuberculatus seedlings; seedlings of both species were transplanted for the second and third timings. Field plots were $10 \times 10 \mathrm{~m}^{2}$ in size and were surrounded by soybean in 2001 and corn in 2002. As shown in Figure 1, a total of $50 \mathrm{~A}$. hybridus and $60 \mathrm{~A}$.

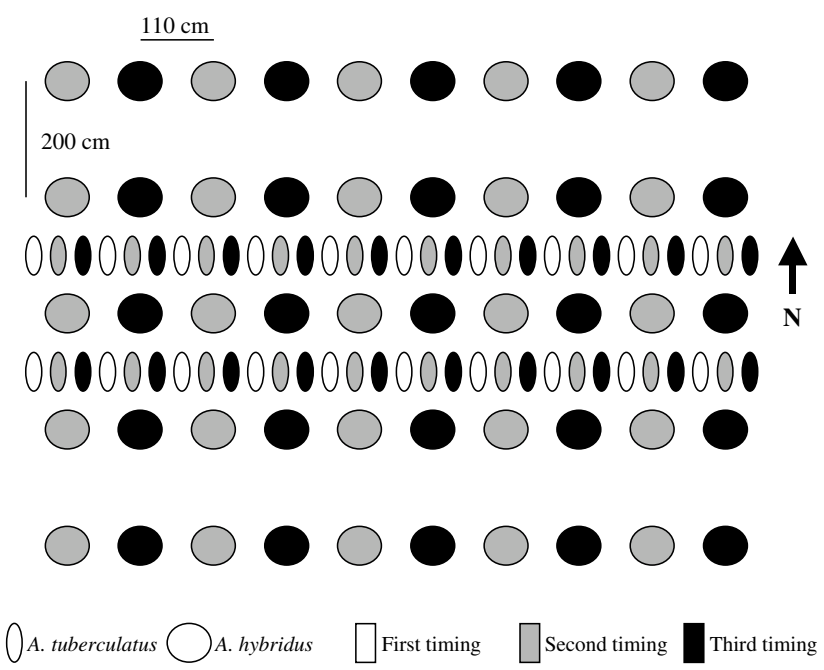

Figure 1 Schematic representation of a field plot showing individual plants and their transplant timings.

tuberculatus plants were transplanted to each plot and arranged in east-west rows. (The prevailing summer wind at the study location is from the southwest.) Plots and surrounding crop rows were regularly inspected for interfering weeds, which were removed upon detection. Flowering dates and sex data were obtained for all plants in the study; $A$. tuberculatus females were removed as soon as identified. All A. hybridus plants were harvested the same day in late September, regardless of the initial transplantation date. The study consisted of two plots for each of two consecutive years of experimentation, for a total of four replications.

\section{Greenhouse screening}

Seed were manually threshed from each $A$. hybridus plant. Total seed production per plant was estimated by weighing the seed obtained and determining the weights of 100-seed aliquots.

Pools of 10000 seeds harvested from parents transplanted at the same time and located in the same row were obtained according to the equation: $A_{x}=10000\left(T_{x} /\right.$ $T_{p}$ ), where $A_{x}$ : seed aliquot from parent $X, T_{x}$ : total seed produced by parent $X, T_{p}$ : total seed produced by all parents in pool. This equation was used to have plants within a sample unit contribute to the pool in a way proportional to their share of total seed production. There were a total of 10 pools per plot $(A$. hybridus plants were transplanted at two different timings and arranged in five rows).

Pooled seeds were placed in $0.2 \%$ agarose solution in a final volume of $50 \mathrm{ml}$, and seeds/agarose mixtures were homogenized by shaking. The $50 \mathrm{ml}$ mixtures were pipetted to trays filled with soil (1:1:1 mixture of soil:peat:perlite), with the first, 23rd and 48th $\mathrm{ml}$ placed in separate control trays. Planted trays were covered with a thin layer of soil and sprayed with chlorimuronethyl at a rate of $90 \mathrm{~g} / \mathrm{ha}$. Control trays were not sprayed, thus emergence in these trays was used to estimate the total number of germinating seeds in sprayed trays of the same seed pool. Seedlings that emerged and grew in 
herbicide-treated trays were designated as putative hybrids. Approximately $10 \%$ of putative hybrids within each pool were randomly selected for molecular analysis of the ALS gene. Of these selected individuals, 5\% were subsequently analyzed using flow cytometry. Once most putative hybrids flowered, about 2 months after screening initiation, plant sex was recorded to determine the sex segregation ratios.

\section{Analysis of the ALS gene}

DNA was extracted from young leaves according to a CTAB procedure modified from that followed by Doyle and Doyle (1990). Polymerase chain reactions (PCRs) were performed to amplify a 450 base-pair region of $A L S$ using alsf1 (5'-AGCTCTTGAACGTGAAGGTG-3') and alsr1 (5'-TCAATCAAAACAGGTCCAGG-3') primers (Foes et al, 1998). Reactions consisted of a total volume of $25 \mu \mathrm{l}$ with $20 \mathrm{mM}$ Tris- $\mathrm{HCl}$ (pH 8.4), $50 \mathrm{mM} \mathrm{KCl,} 2 \mathrm{mM}$ $\mathrm{MgCl}_{2}, 0.2 \mathrm{mM}$ each dNTP, $0.4 \mu \mathrm{M}$ each primer, $1.0 \mathrm{U}$ Taq DNA polymerase (Invitrogen), and about $40 \mathrm{ng}$ genomic DNA. The thermoprofile began with $3 \mathrm{~min}$ at $95^{\circ} \mathrm{C}$; then 40 cycles of $0.5 \mathrm{~min}$ at $95^{\circ} \mathrm{C}, 1 \mathrm{~min}$ at $57^{\circ} \mathrm{C}$, and $1 \mathrm{~min}$ at $72^{\circ} \mathrm{C}$; followed by $5 \mathrm{~min}$ at $72^{\circ} \mathrm{C}$. Half of each PCR reaction $(12.5 \mu \mathrm{l})$ was subjected to digestion with $5 \mathrm{U}$ EcoRV (Invitrogen) in $30 \mu \mathrm{l}$ reactions, with $50 \mathrm{mM}$ Tris$\mathrm{HCl}$ ( $\mathrm{pH} 8.0$ ), $10 \mathrm{mM} \mathrm{MgCl}_{2}$, and $50 \mathrm{mM} \mathrm{NaCl}$. The EcoRV reactions were incubated at $37^{\circ} \mathrm{C}$ for $300 \mathrm{~min}$. Digestion products were fractionated by electrophoresis in $1.2 \%$ agarose gels containing ethidium bromide and photographed atop a UV light box. Plants were classified as $A$. tuberculatus, $A$. hybridus, or hybrid based on the presence of a 374 base-pair fragment, a 444 base-pair fragment, or both fragments, respectively (Tranel et al, 2002).

\section{DNA content analysis}

Nuclei were isolated from putative hybrids and 2-weekold seedlings of maize inbred line W22 (5.35 pg DNA/2C nucleus). About $1 \mathrm{~cm}^{2}$ of fresh leaf tissue from a putative hybrid and 1-cm-long maize stem segment were finely chopped and combined for each isolation. Isolation and staining procedures followed were those indicated previously by Rayburn et al (1992). Flow cytometry was conducted on a Coulter EPICS XL-MCL four-color flow cytometer (Beckman Coulter) equipped with an argon ion laser operated at $15 \mathrm{~mW}$, with an excitation wavelength of $488 \mathrm{~nm}$. At least 8000 nuclei were evaluated per each sample. Plants from the parental $A$. hybridus and $A$. tuberculatus populations were evaluated in each flow cytometer run.

\section{Statistical analyses}

The statistical model used checked the extent to which hybridization frequencies were explained by seed production, row location (row effect), and transplant timing (timing effect) of the mothers. Experimental effects were analyzed using an analysis of variance and considered significant if $P \leqslant 0.05$. Homoskedasticity was checked by plotting studentized residuals versus predicted values. Mean hybridization frequencies were compared using Fisher's least significant difference (LSD) approach for effects having a significant $\mathrm{F}$ statistic. Sex segregation data were compared to the expected 1:1 ratio using a $\chi^{2}$ test. A T-distribution-based $95 \%$ confidence interval was calculated for the mean DNA content for each of the $A$. hybridus and $A$. tuberculatus parents. DNA content values inside these confidence intervals were considered within parental ranges; values between the parental ranges were considered consistent with hybrid identity.

\section{Results}

\section{Field experiment}

Transplantation stress, insect damage, and rodents caused the loss of some plants. However, a total of 120 out of 200 A. hybridus transplants reached maturity and contributed progeny for the analysis (Table 1). Of the transplanted $A$. tuberculatus seedlings, half died as a result of factors such as those listed above and roughly half of the survivors were males. Thus, there were about 15 males per plot. Flowering occurred between the last week of July and the third week of August. Both species flowered during the same time span, indicating that the staggered transplant timings were adequate.

Seed production ranged from an estimated 2000 to 600000 seeds, with an average of 100000 seeds/plant. Average seed production in the first year was more than three times that of the second year, probably due to dryer conditions during the second year.

\section{Herbicide screening}

As explained in Materials and methods, A. hybridus plants that were located in the same row and transplanted at the same time were pooled together. Since a plant could be located in one of five possible rows and transplanted at one of the two possible times, there were 10 possible pools for each of the four plots (reps). Individuals contributing to 36 out of the possible 40 seed pools were available for screening. Each pool was comprised of seeds harvested from an average of three parents, although some pools had only one contributing parent and others five. Overall germination in controls (nontreated trays) was estimated at $78 \%$ of the seed planted. A total of 3662 plants (putative hybrids) emerged and grew in herbicide-treated trays, $1.3 \%$ of the total estimated number of germinating seeds (Table 1). Putative hybrids comprised $0.0-5.9 \%$ of the estimated germinating seeds for any one seed pool. Parental seed production did not correlate significantly with putative hybrid frequencies $\left(P=0.24, \mathrm{H}_{0}: r=0\right)$. Likewise, transplantation timing did not explain any of the observed frequency differences $(P=0.3)$. However,

Table 1 Summary table for A. hybridus parents and hybrid progeny

\begin{tabular}{|c|c|c|}
\hline Year & 2001 & 2002 \\
\hline Seedlings transplanted & 100 & 100 \\
\hline Plants harvested & 60 & 60 \\
\hline Seed produced ${ }^{a}$ & 9144500 & 2879400 \\
\hline Seed evaluated ${ }^{a}$ & 160000 & 200000 \\
\hline Seed germinated ${ }^{a}$ & 137140 & 142190 \\
\hline Putative hybrids obtained & 1109 & 2553 \\
\hline Putative hybrids analyzed at $A L S$ gene & 111 & 255 \\
\hline (\% confirmed) & (98) & (100) \\
\hline Putative hybrids analyzed cytogenetically & 7 & 10 \\
\hline (of confir & (100) & $(100)$ \\
\hline Total number of hybrids produced ${ }^{a}$ & 72600 & 51700 \\
\hline
\end{tabular}

aEstimated values. 


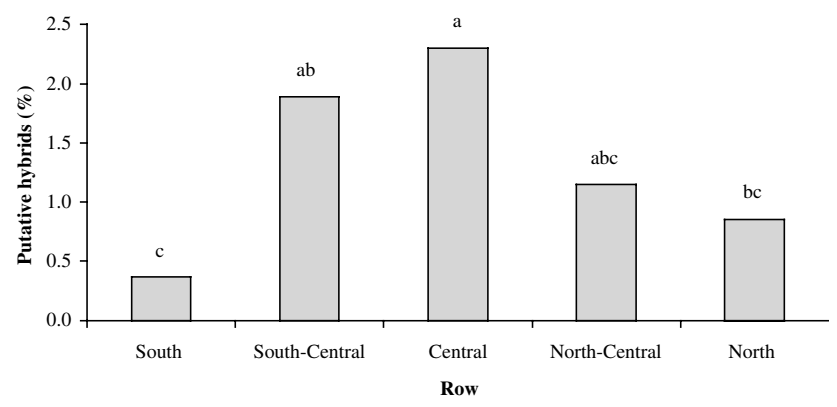

Figure 2 Hybridization frequency based on herbicide selection. Letters above each bar are indicative of LSD groupings $(P=0.05)$.

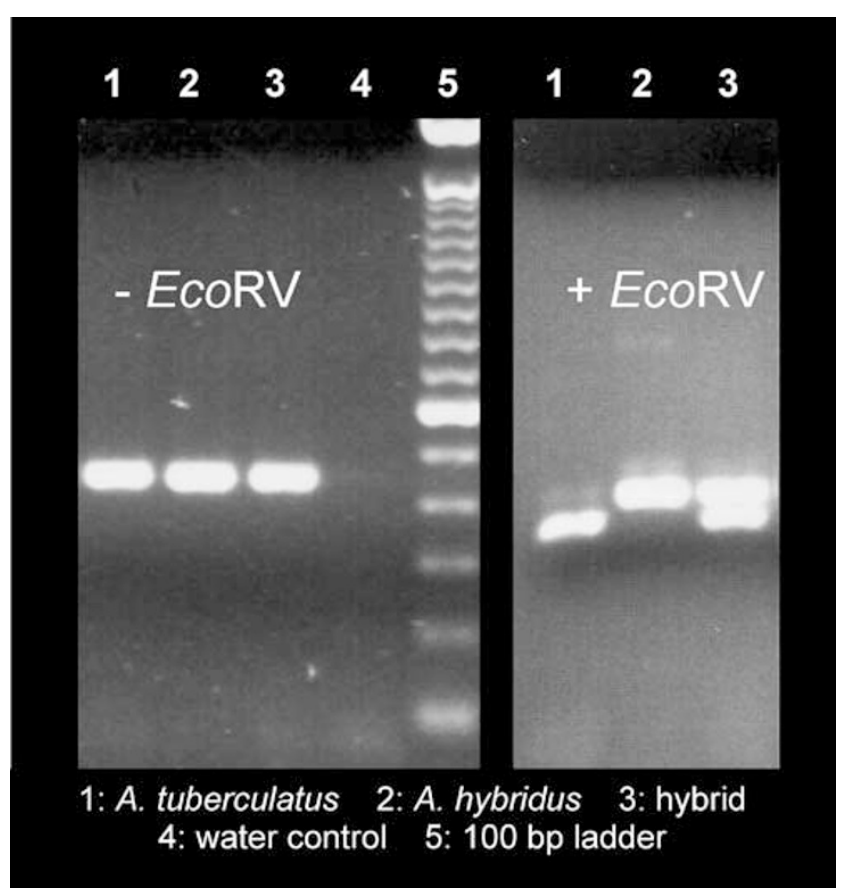

Figure 3 Confirmation of putative hybrids by ALS gene analysis. Gels show a PCR-amplified fragment of ALS before (-EcoRV) and after $(+E c o R V)$ digestion for representative parental and hybrid plants.

there was a significant row effect $(P=0.02)$. Figure 2 shows the mean putative hybrid frequencies for each row location. As expected, central rows showed higher hybrid frequencies than outer rows.

\section{$A L S$ analysis}

Figure 3 shows representative EcoRV digestion band patterns observed for PCR products using DNA from parental plants and herbicide-resistant progeny. Of the 366 survivors (putative hybrids) evaluated, only two did not show double bands indicative of hybrid origin. Of these two, the ALS gene analysis suggested one to be $A$. hybridus and the other A. tuberculatus.

\section{DNA content}

DNA content of selected survivors that were confirmed hybrids by $A L S$ gene analysis ranged between 1.23 and

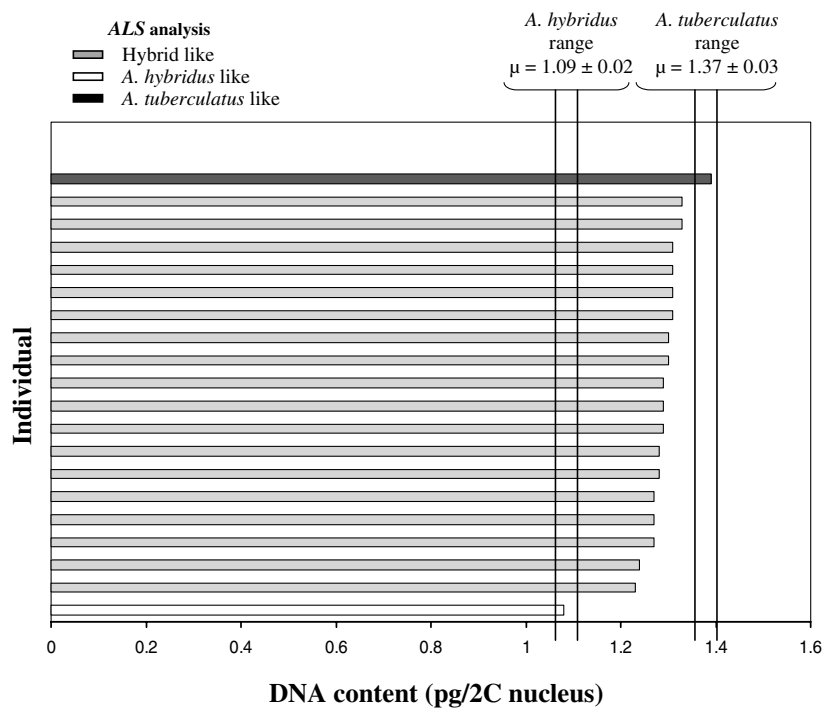

Figure 4 DNA content values of selected herbicide survivors with their corresponding ALS analysis results.

Table 2 Hybrid sex segregation at different plant densities

\begin{tabular}{lcccr}
\hline Hybrids per pool & Flowered (\%) & Males & Females & \multicolumn{1}{c}{$\mathrm{P}^{\mathrm{a}}$} \\
\hline $1-100$ & 78 & 452 & 431 & 0.48 \\
$101-200$ & 74 & 302 & 211 & $<0.01$ \\
$>200$ & 70 & 717 & 565 & $<0.01$ \\
\hline
\end{tabular}

a $P$-values of the $\chi^{2}$ test statistics for male-to-female ratio $\left(\mathrm{H}_{0}=1: 1\right)$.

$1.33 \mathrm{pg} / 2 \mathrm{C}$ nucleus (Figure 4). None of the plants confirmed hybrids by ALS gene analysis had a DNA content value that was within the $95 \%$ confidence ranges of the two parents. In contrast, both plants that gave nonhybrid EcoRV band patterns were included in the flow cytometry analysis, and their DNA content values were within parental ranges.

\section{Sex segregation}

In all, $73 \%$ of the survivors flowered and all but six were dioecious. There were a total of 1471 males and 1207 females scored, more males and fewer females than expected for a 1:1 ratio $(P<0.01)$. However, if pools with more than 100 survivors are excluded from the analysis (10 out of 36 pools), the sex segregation ratio is not dissimilar to the expected 1:1 (Table 2). Flowering in these pools was $78 \%$, while it was $70 \%$ in the excluded trays.

\section{Discussion}

Parental biotypes that are either homozygous resistant or susceptible to ALS inhibitors can be used to obtain heterozygous progeny detectable by herbicide selection, providing a high-throughput approach to hybrid identification. By default, the approach also unmasks the acquisition of the herbicide-resistance trait in hybrid progeny.

Using this approach, the study established field hybridization frequencies between $A$. hybridus and $A$. 
tuberculatus (males) of up to $5.9 \%$, with mean frequencies for rows at different distances from $A$. tuberculatus ranging from 0.4 to $2.3 \%$. As expected, hybrid frequencies decreased as the distance between parents increased (Figures 1 and 2). These estimations are based on $A L S$ allele movement from male $A$. tuberculatus to $A$. hybridus parents, as detected by herbicide selection on $A$. hybridus progeny. Herbicide-resistant progeny could arise from alternative scenarios, namely: from external (outside of field plot) Amaranthus pollen (not $A$. tuberculatus) carrying a resistance-conferring ALS allele, from resistance segregating at low frequencies in the A. hybridus parental population used, and/or from herbicide treatment escapes that are not really resistant or hybrid in nature. Therefore, several steps were taken to confirm the fidelity of the herbicide selection assay.

Seeds were harvested from the self-pollinating parent, A. hybridus; hence the vast majority of escapes were expected to be monoecious. However, hybrids were described previously as dioecious (Murray, 1940; Tranel et al, 2002). Only six $(0.4 \%)$ monoecious plants were identified among the flowering herbicide survivors, confirming that herbicide escapes did not significantly impact hybridization frequency estimates. The herbicide rate used was six times higher than the recommended field rate, thus reducing the chance for escapes among susceptible progeny. Additionally, herbicide-spray contact problems associated with high seedling density conditions were minimized by using pre-emergence (soil-applied) treatments.

Similarly, the fact that almost all survivors were dioecious suggested that observed frequencies can neither be explained by resistance segregating in the $A$. hybridus parental population nor by contamination with external pollen from herbicide-resistant $A$. hybridus. Likewise, pollination by other monoecious amaranths is unlikely because hybrids among monoecious species are monoecious themselves (Murray, 1940).

About $27 \%$ of the herbicide survivors did not flower (likely because of stress caused by high seedling densities in relatively shallow trays); in these cases, dioecism could not be used to support hybrid identity. Prior ALS sequencing data from both parental populations revealed the existence of a species-specific polymorphism. Whether carrying a herbicide-resistance-conferring mutation or not, a restriction site recognized by EcoRV endonuclease has been identified in A. tuberculatus ALS alleles, which is absent in A. hybridus alleles. This marker was used successfully by Tranel et al (2002) to show hybrid identity. ALS analysis on a random sample of the surviving population showed that almost all putative hybrids (364 out of 366) had both parental alleles, regardless of whether they flowered or not.

As a final confirmation of hybrid identity, DNA contents were determined for a subset of the herbicide survivors. Nuclear DNA content analysis on several $A$. hybridus and $A$. tuberculatus populations has established $2 \mathrm{C}$ values to be fairly consistent, with mean values of 1.04 and $1.34 \mathrm{pg} /$ nucleus for $A$. hybridus and $A$. tuberculatus, respectively (Jeschke et al, 2003). The nonoverlapping nature of these estimates allows for the use of flow cytometry in identification of hybrid progeny. As can be seen in Figure 4, observed DNA content values were within the intermediate range (1.12-1.33 pg/2C nucleus) expected of hybrids. Furthermore, the two escapes identified by means of $A L S$ analysis had DNA content values within parental ranges and corresponding to the identities suggested by ALS evaluation (Figure 4).

Although DNA contents of suspected hybrids were within the expected range (ie, between the parent values), it cannot by itself determine hybrid identity. Moreover, no one experimental approach by itself is sufficient to unequivocally determine the hybrid nature of the tallied progenies. Rather, herbicide resistance, ALS analysis, DNA content, and flower type combined testify to the accuracy of the reported hybridization frequencies.

Overall male-to-female ratio among obtained hybrids was dissimilar from the previously reported 1:1 (Murray, 1940). This was most likely due to the conditions in which hybrids grew. Trays with fewer than 100 hybrids showed expected segregation (Table 2). In high-density trays, flowering percentages were lower, as nutritional and other stresses probably stalled development. At low flowering percentages, sex segregation ratios have a propensity to be male-biased, since males tend to flower earlier. In any case, the data do not suggest that any one sex is clearly predominant among hybrids.

Hybridization between $A$. hybridus and $A$. tuberculatus has been reported previously (Murray, 1940; Tranel et al, 2002); nevertheless, field hybridization frequencies obtained in this study were much higher than anticipated. As shown in Table 1, 124300 hybrids were estimated to have been produced in the field plots included in this study. Franssen et al (2001) obtained a hybridization frequency of less than $0.1 \%$ (an estimated 440 hybrids from roughly 4 million flowers) between $A$. tuberculatus and $A$. palmeri under controlled greenhouse crosses. These species are not only obligatory outcrossers but also belong to the same subgenus (Robertson, 1981). Yet, hybridization frequencies many times higher were observed herein, perhaps indicating closer evolutionary proximity between $A$. tuberculatus and $A$. hybridus than between $A$. tuberculatus and $A$. palmeri. This view is consistent with previous findings from phylogenetic analysis of the Amaranthus genus (Lanoue et al, 1996).

As previously stated, A. hybridus is thought to be predominantly self-pollinated. Its outcrossing rate is unknown; however, a study done with grain amaranths closely related to $A$. hybridus reported intraspecific outcrossing frequencies of about 10\% (Agong and Ayiecho, 1991). Assuming a similar outcrossing rate for A. hybridus, the highest hybridization frequency obtained in this study (5.9\%) was equivalent to approximately half of its intraspecific outcrossing rate.

Perhaps the full extent of hybridization among $A$. hybridus and $A$. tuberculatus will be apparent when evaluating frequencies in the reciprocal direction $(A$. tuberculatus as a female), a scenario in which the mother is not capable of self-pollination. However, this is a harder direction to appraise hybridization under field conditions due to the widespread ALS-inhibitor resistance in A. tuberculatus (Patzoldt et al, 2002) and the almost ubiquitous nature of its pollen in Illinois fields (unpublished data). Thus, herbicide selection assays will tend to overestimate hybridization frequencies. Instead, a high-throughput molecular approach should be used to obtain accurate hybrid estimates among $A$. tuberculatus seeds. 
The evolutionary implications of the magnitude of hybridization reported herein are necessarily linked to the fate of hybrids. Currently, studies looking at overall hybrid fitness and fertility are being undertaken. Previous reports have shown that although hybrid fertility is greatly reduced backcross progeny can be obtained, with fertility increasing in subsequent generations (Tranel et al, 2002). Moreover, for hybrids to be evolutionary meaningful, they need to show a comparative advantage with respect to the original population (Abbott et al, 2003). The acquisition of herbicide resistance via single gene movement, combinatorial gene action, or other hybrid-related mechanism could provide hybrids with such comparative advantage. In the presence of herbicide selection pressures, herbicide resistance in the hybrids becomes a competitive advantage with respect to nonresistant populations. In the context of this study, hybrids survived a sulfonylurea herbicide treatment, whereas their nonhybrid siblings (A. hybridus) died.

Estimated frequencies presented in this study are not meant to provide an all-encompassing population parameter, but rather a sense of magnitude. Besides, because hybridization frequencies were expected to be very low, the experimental plot layout was such as to promote hybridization. To ensure detectable hybridization frequencies, a large number of $A$. tuberculatus pollen donor plants were grown in close proximity to $A$. hybridus parents. Thus, results provided by this study are a better indication of the maximum potential for hybridization under field conditions than that of actual hybridization under agronomic settings. However, $A$. hybridus and $A$. tuberculatus plants are commonly found in close proximity - and synchronously flowering - in Illinois fields, leading to the belief that estimates reported herein can be accomplished under real conditions.

Combined with future data on the fitness of hybrids and their subsequent generations, the current information can be used to assess the relative advantage of hybridization in the adaptive ability of weedy amaranths. Hybridization frequency is a component of the rate of interspecific gene introgression; therefore, this information can be used to more accurately model herbicide resistance development in populations of the studied species. Furthermore, the obtained frequencies were many times higher than the generally expected rate of mutation. Consequently, even minimal fertility among hybrid progeny would support a role for adaptive hybridization in some weedy Amaranthus species, at least with respect to acquisition of monogenic herbicide resistance.

\section{Acknowledgements}

This material is based on work supported by the USDA under Award No. 2001-35320-11002 and by a grant from the Illinois Soybean Program Operating Board.

\section{References}

Abbott RJ, James JK, Milne RI, Gillies ACM (2003). Plant introductions, hybridization and gene flow. Phil Trans $R$ Soc Lond B 358: 1123-1132.

Agong SG, Ayiecho PO (1991). The rate of outcrossing in grain amaranths. Plant Breed 107: 156-160.
Darmency H (1996). Movement of resistance genes among plants. In: Brown TM (ed). Molecular Genetics and Evolution of Pesticide Resistance, American Chemical Society: Washington DC. pp 209-220.

Doyle JJ, Doyle JL (1990). Isolation of plant DNA from fresh tissue. Focus 12: 13-15.

Ellstrand NC (2001). When transgenes wander, should we worry? Plant Physiol 125: 1543-1545.

Foes MJ, Liu L, Tranel PJ, Wax LM, Stoller EW (1998). A biotype of common waterhemp (Amaranthus tuberculatus) resistant to triazine and ALS herbicides. Weed Sci 46: 514-520.

Franssen AS, Skinner DZ, Al-Khatib K, Horak MJ, Kulakow PA (2001). Interspecific hybridization and gene flow of ALS resistance in Amaranthus species. Weed Sci 49: 598-606.

Gressel J (2002). Molecular Biology of Weed Control, Taylor \& Francis: London. pp 86-87.

Guttieri MJ, Eberlein CV, Mallory-Smith CA, Thill DC (1996). Molecular genetics of target-site resistance to acetolactate synthase inhibiting herbicides. In: Brown TM (ed). Molecular Genetics and Evolution of Pesticide Resistance, American Chemical Society: Washington, DC. pp 10-16.

Hager AG, Wax LM, Bollero GA, Simmons FW (2002). Common waterhemp (Amaranthus rudis Sauer) management with soilapplied herbicides in soybean (Glycine max (L.) Merr.). Crop Prot 21: 277-283.

Hager AG, Wax LM, Simmons FW, Stoller EW (1997). Waterhemp Management in Agronomic Crops. University of Illinois: Urbana, IL. p 12.

Jasieniuk M, Maxwell BD (2001). Plant diversity: new insights from molecular biology and genomics technologies. Weed Sci 49: 257-265.

Jeschke MR, Tranel PJ, Rayburn AL (2003). DNA content analysis of smooth pigweed (Amaranthus hybridus) and tall waterhemp (A. tuberculatus): implications for hybrid detection. Weed Sci 51: 1-3.

J $\varnothing$ rgensen RB, Andersen B (1994). Spontaneous hybridization between oilseed rape (Brassica napus) and weedy B. campestris (Brassicaceae): a risk of growing genetically modified oilseed rape. Am J Bot 81: 1620-1626.

Lanoue KZ, Wolf PG, Browning S, Hood EE (1996). Phylogenetic analysis of restriction-site variation in wild and cultivated Amaranthus species (Amaranthaceae). Theor Appl Genet 93: 722-732

Murray MJ (1940). The genetics of sex determination in the family Amaranthaceae. Genetics 25: 409-431.

Patzoldt WL, Tranel PJ, Hager AG (2002). Variable herbicide response among Illinois waterhemp (Amaranthus rudis and $A$. tuberculatus) populations. Crop Prot 21: 707-712.

Pratt DB, Clark LG (2001). Amaranthus rudis and A. tuberculatus - one species or two? J Torrey Bot Soc 128: 282-296.

Rayburn AL, Auger JA, McMurphy LM (1992). Estimated percentage constitutive heterochromatin by flow cytometry. Exp Cell Res 198: 175-178.

Rieger MA, Potter TD, Preston C, Powles SB (2001). Hybridization between Brassica napus L. and Raphanus raphanistrum L. under agronomic field conditions. Theor Appl Genet 103: $555-560$.

Robertson KR (1981). The genera of Amaranthaceae in the southeastern United States. J Arnold Arbor 62: 267-314.

Sauer JD (1957). Recent migration and evolution of the dioecious amaranths. Evolution 11: 11-31.

Sauer JD (1967). The grain amaranths and their relatives: a revised taxonomic and geographic survey. Ann Missouri Bot Gard 54: 102-137.

Seefeldt SS, Zemetra R, Young FL, Jones SS (1998). Production of herbicide-resistant jointed goatgrass (Aegilops cylindrica) $\times$ wheat (Triticum aestivum) hybrids in the field by natural hybridization. Weed Sci 46: 632-634.

Spencer LJ, Snow AA (2001). Fecundity of transgenic wild-crop hybrids of Cucurbita pepo (Cucurbitaceae): implications of crop-to-wild gene flow. Heredity 86: 694-702. 
Tranel PJ, Wassom JJ, Jeschke MR, Rayburn AL (2002). Transmission of herbicide resistance from a monoecious to a dioecious weedy Amaranthus species. Theor Appl Genet 105: 674-679.

Wax LM (1995). Pigweeds of the Midwest - distribution, importance, and management. Proc Iowa Integr Crop Manag Conf 7: 239-242.
Wetzel DK, Horak MJ, Skinner DZ, Kulakow PA (1999). Transferal of herbicide resistance traits from Amaranthus palmeri to Amaranthus tuberculatus. Weed Sci 47: 538-543.

Whitton J, Wolf DE, Arias DM, Snow AA, Rieseberg LH (1997). The persistence of cultivar alleles in wild populations of sunflowers five generations after hybridization. Theor Appl Genet 95: 33-40. 